\title{
The Influence of Organisational Culture on Leadership: A Case Study of Baidu Corporation, China
}

\author{
Yinfei Xue ${ }^{1}$ \\ ${ }^{1}$ Queen Mary University of London, London, UK \\ Correspondence: Yinfei Xue, Queen Mary University of London, London, UK.
}

Received: October 25, 2019

Accepted: November 15, 2019

Online Published: December 5, 2019

doi:10.20849/ajsss.v4i4.676

URL: https://doi.org/10.20849/ajsss.v4i4.676

\begin{abstract}
Corporate culture and leadership are central to the performance of the firm in many ways. Culture outlines essential practices and patterns that guide the leaders' control. The connection between cultural influences on corporate leadership has been examined from various perspectives. A productive culture can determine the success of a company, and its interaction with leadership is an exciting area of examination in research.

Objectives of the Study: This study's primary aim was to establish how the corporate culture influences leadership in various ways in the corporate environment using the case study of Baidu Corporation in China. Also, the study intended to examine different leadership styles and influence on organisational performance.

Methods: The study was carried out in Baidu, Inc., China, a target of 100 participants using mixed-structured email questionnaire. The study also utilised various research techniques, including the mixed-method method in the study process.

Results and Findings: The study found that there is a secure link between corporate culture and the kind of leadership adopted in an organisation. Also, the study established various aspects of employee opinion, with evidence that employees favour certain leadership styles such as transformational leadership style over others.
\end{abstract}

Keyword: Baidu, leadership, corporate culture

\section{Introduction}

\subsection{Background}

Two of the most researched topics that intertwine each other and have been a subject of continued research are organisational culture and leadership. The cultural context of great significance on an organisation, and determines various aspects such as practices, beliefs, and set of norms that impacts an organization daily. As noted by Tsai (2011), organisation culture is defined as the set of values and beliefs that exists in a firm for an extended period. Organisation culture is fundamental since it influences and shapes employees' attitudes and beliefs towards the achievement of set goals and objectives. Moreover, the culture of an organisation is the broader environment, which defines and influences the function of the leadership. In most occasions, the leadership of an organisation shapes its environment and directly affects beliefs and practices. As a result, this demonstrates the significance of leadership and culture, which makes the concepts subject to further discussion.

Leadership and culture are strongly interdependent on each other, and as highlighted Nikcevic (2016), this makes it difficult to determine the concept that influences the other. Nevertheless, researchers can approach this area by clearly defining their goals and objectives. In most research articles, researchers show that the two concepts intertwine with each other, but more emphasis is given on culture because of how it shapes beliefs and leadership styles. The conflicting nature of the concepts enables researchers to examine the two elements from different angles while applying diverse theoretical schools. One researcher Klein et al. (2013), affirmed that various leadership styles either affects or shapes organisational cultures, in addition to practices. Nevertheless, research by Nikcevic (2016) shows that analytical approaches such as structural interpretivism and functionalism show an intertwined association between the concepts, which means that one thought can influence the other. In this research study, the aim is to focus on cultures as the primary determinant of leadership, and it draws from theoretical analysis from different pieces of literature that underpin the relationship. 


\subsection{Research Question}

1. How does the concept of culture influence the leadership in Baidu Corporation?

2. How does the cultural impact on leadership shape the performance and direction of the firm?

\subsection{Aims and Objectives}

- To develop a distinctive connection between the culture of an organisation and its leadership.

- Determine and underpin the different ways that the culture of an organisation affects the style of leadership in a firm or corporate environment.

- To investigate and demonstrate how organisational culture affects leadership and how it contributes to shaping the direction of a corporation, such as Baidu.

\section{Literature Review}

\subsection{Overview}

Just like any social set-up with a set of practices and norms that guide social interactions, corporate culture is a strong determinant of business identity. According to Alnasseri et al. (2013), organisational culture promotes identity of the firm hence upholding the critical distinction from other competitors as a crucial way of enhancing competitiveness. The significance of having a distinct corporate culture has been on the rise in recent times. For instance, Aydin (2018) noted that with an influential organisational culture, corporate entities could firmly enhance proper control of their leadership needs and styles. In China, for example, there has been an apparent effort by the government to improve organisational culture as a central way of enhancing proper leadership and productivity (Hawes \& Chew, 2011). The rising consideration of culture as a key component in the performance of the firms underlines its significance in the modern-day business environment. Also, issues concerning multiculturalism, diversity and enhanced performance among the employees are factors directly affected by cultural and leadership relationships.

On the other hand, it is imperative to highlight that the influence of culture on leadership in the corporate world differs from one industry to another, which in turn, affects the ultimate performance of the businesses. Zhang and Liu (2006) had earlier noted ineffective organisational cultures in industries such as the construction industry in China, which led to reduced profitability and lack of equality. However, Hawes and Chew (2011) highlighted a change in the practices with the government recognising efficient organisational culture to spearhead economic growth. The underlying consensus from the majority of the research in literature is that cultures, as well as leadership within an organisation, have a powerful sway on performance, promotion of ideas and enhancing understanding (e.g. Hawes \& Chew, 2011; Alnasseri et al. 2013; Nikcevic, 2016; Aydin, 2018). For this reason, regardless of the industry of operation, a proper corporate culture and leadership styles are imperative for the success of the firms.

Thus, in this literature analysis, this research places particular concentration on the three significant scenarios. They include the relationship between organisational culture and leadership as expounded in the literature (e.g. Tsai, 2011; Nikcevic, 2016; Aydin, 2018). Also, another substantial factor to consider is the influence of the organisational culture on the leadership styles (e.g. Aripin et al. 2013; Akhavan et al. 2014; Hersey \& Blanchard, 2014; Aydin, 2018). The final analysis involves an exploration of the impacts of the corporate culture on leadership and how it shapes the organisation (e.g. Pennington et al. 2003; Szczepańska-Woszczyna, 2015; Lousa \& Monico, 2018). From the literature, it is evident that culture and leadership are strongly intertwined factors that influence organisational performance. The interdependence of these aspects means that while cultural influence determines the kind of leadership adopted within a firm, it is also possible that culture could easily be manipulated or changed by a leader (Aydin, 2018). Nonetheless, organisational culture remains an integral factor in determining the type of leadership styles and techniques that involves bureaucratic systems or transformational leadership styles (Nikcevic, 2016). The influence of culture on leadership, however, is a prevalent scenario in most multinationals across the world. It is considered as a catalyst for enhanced organisational performance as well as job satisfaction among the employees.

\subsection{The Relationship Between Organisational Culture and Leadership}

The existing relationship between organisational culture and leadership is productive, wherein the two concepts are dominant in the formation of a robust corporate culture. This has led to different researchers trying to research on the characteristics of the relationship and what makes corporate culture and leadership style so intertwined (Aydin, 2018). The overall relationship between the two concepts could be two-fold, wherein culture significantly influences leadership, whereas leadership, on the other hand, influences culture (Nikcevic, 2016). 
The literature tends to support this two-fold nature. Different scholars have tried to study on this two-fold nature and varied other activities, such as Lousa \& Monico (2018), Pennington et al. (2003), Rahmisyari (2015), and Klein et al. (2013). On the other hand, other scholars have taken a different approach in studying the impact of culture on organisational leadership; these scholars include Nikcevic (2016), Tsai (2011), Aydin (2018), and Al-Tameemi \& Alshawi (2014). The different approaches taken by these scholars demonstrate that no matter what there is a deep connection between organisation and culture. For instance, the differing approaches, as noted by Nikcevic (2016) shows the degree of inter-dependence between the concepts and why it is problematic to establish a concept that influences the other.

On the contrary, there is enough evidence in the literature to highlight specific functions of both culture and leadership. For example, in a simple corporate setting, culture influences work processes, beliefs, and diverse activities from the employees and managers perspectives (Tsai, 2011). Similarly, organisational leadership is essential in developing command measures whose aim is to spearhead the corporate culture of an organisation and other related activities (Akhavan et al., 2014). A firm is built based on a particular culture. For researchers arguing from the interpretivism perspective, they note that the organisational belief lies in the fact that culture is a constituent of the whole organisation. Additionally, every organisation's aspects is a reflection of its culture (Allaire \& Firsirotu, 1984). On the other hand, the researchers arguing from the perspective of structural-functionalism highlights that organisation exists, but culture is more of an asset to that organisation whereby the leadership can control and shape it to have maximum influence (Nikcevic, 2016). The two different views and position offers a clear indication that there is a robust and challenging relationship between the concepts of leadership and culture, and none exists without the other in a corporate environment.

Therefore, the common understanding and point of views from the literature are that culture influences the organisational leadership, but the latter also determines the outcomes of the former. For example, Aydin (2018) underlined that while most researchers believe that the organisation is the culture itself, it remains vulnerable to possible manipulation. The cultural influence of a corporate entity is so strong that it can determine the leadership success or mishaps of the leaders, which explains the cases of success in one company and failure in another by the top executives (Alnasseri et al., 2013). Serious concerns have often been associated with the cultural standpoint of some organisations which has necessitated flexibility as a critical factor. In certain instances, culture can be manipulated to a certain degree by the leaders, which could be essential or detrimental (Aydin, 2018). The influence of organisational culture is robust such that it can determine the success or failure of leadership in various ways.

For instance, if a leader takes charge of an organisation with less progressive visions and maintains it, there is a high chance for failure. If he/she changes some aspects of the culture positively, success is likely to follow. On the same line, if any corporate executive takes charge of an organisation with a progressive culture and tries to manipulate it, there is a likelihood of leadership failure. These scenarios are just a reflection of various dynamics of the culture-leadership relationship in a corporate environment as examined in literature by different scholars (e.g. Tsai, 2011; Alnasseri et al. 2013; Nikcevic, 2016; Aydin, 2018). Thus, for the corporate stakeholders and leaders, having a strong understanding of these dynamics is instrumental in decision-making and maintenance of the appropriate corporate culture.

\subsection{The Influence of Organisational Culture on Leadership Styles}

Organisational culture significantly influences leadership styles. Aripin et al. (2013) organisations exist because of certain set of practices that affect the performance of employees and managers while dispensing their managerial duties. Tsai (2011) points out that organisational culture is made up of different tangible and intangible beliefs and perceptions, which contributes to the functionality of various aspects of the organisation. Also, Nikcevic (2016) ascertains that according to the interpretivism approach, culture positively impacts different functionalities of an organisation. Leadership foundations in an organisation adhere to a particular cultural guideline. Although the top management in the organisation has the duty and responsibility to issues commands and directions, it has to do so based on the cultural framework that defines the organisation.

When a new organisation is formed, there is a new cultural framework developed. However, such a framework is not static as it is subjected to changes as highlighted in research by Al-Tameemi and Alshawi (2014). In such a case, the formation of a leadership style to accompany and uphold a culture is essential to keep the culture intact or improve it to the desired culture. In most cases, organisations that have excelled often adhere to the set of practices and activities that have been shaped by the concept of culture. Most likely, these practices and activities constitute the cultural formation of an organisation (Tsai, 2011). Rahmisyari (2015) highlights that in the case the perfoamance of a firm is unimpressive, the management mitigates that by changing certain patterns of 
practices that will significantly match organisational culture, and will positively impact results. As a result, the existing cultural formations are directly affected by the leadership style that a firm deploys, for it upholds required values.

Conversely, in most organisations, elements such as the overall leadership and employee performances' are dependent on its cultural context. A vibrant culture defines itself and can influence the pace of a firm's performance without maximum efforts from its leadership (Aripin et al., 2013). As noted before in this discussion, the business and its practices exist with a culture born during the business's inception, and the continued role of the leadership/management is for the enhancement of optimum control. Akhavan et al. (2014) elaborated on the leadership styles and the concepts of educational leadership that are necessary when both the commanding and supportive behaviour are high.

The implementation of command leadership is when the command behaviour is high, whereas supportive behaviour is low. The supportive leadership style in an organisation is used whenever the supportive behaviour is high, whereas the command behaviour is weak. Lastly, a leadership style such as authoritative is critical when the command behaviour and supportive behaviour are at their lowest. Hersey \& Blanchard (2014) defines organisational culture as the behavioural elements and practices portrayed by employees that compels praise or appraisal from the management. Akhavan et al. (2014) while referring to the applications of different leadership styles, the researchers noted that culture is significant, and it subsequently influences the leadership of an organisation.

Moreover, corporate culture affects the behavioural and perceptions of its subjects that include the management and employees. As a result, the performance of an organisation becomes increasingly dependent on its concept of culture embedded in its way of doing things. Based on this perspective, culture entails the inner feelings that are unseen by experience in the organisation's systems of operation. Aydin (2018) supports that notion by highlighting that culture in the same way in a community affects the whole composition of a human being. As such, with these assertions in mind, the formulation leadership styles are dependent on the existing cultural practices in the organisation (Akhavan et al. 2014). For instance, a firm is free to utilise supportive, authoritative, command, or educational leadership approaches based on the cultural composition of a firm.

\subsection{Impacts of Corporate Culture on Leadership and How They Shape Organisations}

Whenever culture has an impact on the way organisations formulate and aligns its leadership strategies, it leads to the emergence of new transformations. Al-Tameemi and Alshawi (2014) reveal that culture has a transformative effect, but it depends on the leadership style of a firm. Pennington et al. (2003) add by noting that leadership could only be observed and understood based on the concept of culture. Therefore, it is worth noting that everything that the organisational culture must underpin a leadership implements. For instance, culture promotes behaviours' such as information and knowledge dissemination and it determines the best way to such functionality (Akhavan et al. 2014). In the organisation context, it is the culture that will prompt the management to promote specific innovative actions and practices, or particular improvement in the performance of its employees (Lousa \& Monico, 2018: Aripin et al. 2013). In brief, it is the culture of an organisation that will determine the new adoptions or improvements to be made on the existing organisational practices. The management of an organisation or its leadership style in adherence to its cultural dimensions is critical in shaping the corporate culture of an organisation.

Conversely, it is imperative to underline that the effectiveness of culture on the leadership of any organisations depends on the systems set in place to advance the cultural needs. Nikcevic (2016) highlighted that some organisations have different norms and practices in their leadership patterns. While some favour the bureaucratic system that places massive powers to top executives, others favour equal participation styles. Companies aim to enhance strong entrepreneurial influence, with innovative cultures to spearhead the achievement of organisational objectives, and the corporate culture is at the core of all the strategies (Szczepańska-Woszczyna, 2015). The changing sphere of the business has led to significant changes in cultural adoptions of many corporates. Globalisation is an emerging factor buoyed by technology. Concerning the globalisation aspect, Jalal (2017) discussed the adoption of multiculturalism in most multinational enterprises. Cultural changes are a vital component of organisational progress (Aydin, 2018), and most multinational corporations bank on cultural diversity and multiculturalism to enhance job performance and satisfaction.

Therefore, the impact of corporate culture on leadership is manifested in a variety of ways, which in turn shapes the organisation towards the desired objectives. According to Tsai (2011), organisational culture directly shapes leadership behaviour, which in turn contributes to job satisfaction. Culture has become an essential cornerstone of corporate growth, and this has been evident as firms strive to adopt measures that satisfy the needs of their 
employees (Jalal, 2017). Increasing dynamics such as industry competition, workforce retention, and the demands of globalisation have necessitated cultural interventions in shaping the leadership needs for prosperity (Aydin, 2018). Thus, the impact of corporate culture on leadership is an area on the rise, which is perceived as a strong influence performance and job satisfaction.

\subsection{Theoretical Analysis}

The two concepts of leadership and culture have been studied extensively under the subjection of different theoretical perspectives and in different ways. For example, Dauber et al. (2010) developed a generic theory of organisational culture wherein the researchers placed on the specific domain the following elements corporate culture and identity, the strategy, processes, organisational structure, design and the organisational performance and behaviours'. The different elements on the domain affect the way an organisation controls its cultural space and designs its corporate leadership structures.

The most significant theoretical analysis of leadership and culture has been demonstrated when examining structural interpretivism and functionalism perspectives. Researchers Allaire and Firsirotu (1984) looked at different elements of organisational culture with emphasis on structural functionalism. According to the writers, the structural functionalists like Radcliffe Brown believed that culture is an adaptive mechanism by which a group of people are allowed to exist within an environment with a set of guidelines to control their existence. Structural functionalism considers culture as a fundamental asset controllable by the styles of leadership that a firm adopts. Also, structural-functionalism considers culture to engross cognitive aspects, which enables the people within it to express various behavioural issues and practices (Nikcevic, 2016). However, some scholars have emphasised leadership above culture, insisting on the inspiration of the leaders to create new cultural patterns. For example, Pennington et al. (2003) underlined the role that leaders play in creating culture, and also through leadership, a lot of new patterns of practices can be formulated to adapt to the organisational needs. Conversely, the overall consensus in the literature that organisations exist with culture means that leaders can only enhance some changes instead of creating new cultures (Tsai, 2011). There could be massive problems for the leaders who attempt to manipulate organisational culture to suit their leadership styles and techniques. They involve either leadership failures by the promotion of a poor culture that may only lead to poor performance.

On the other hand, according to Boromisza-Habashi (2012), the interpretivism approach places culture above leadership, such that the organisation itself is "culture" and all the activities enshrined in it reflect the functionality of that particular culture. The functionality of the culture determines the various aspects of leadership and the outcomes in terms of the performance for the organisation (Tsai, 2011). In recent times, the increasing interest in corporate culture has been seen as key to successful business performance (Hawes \& Chew, 2011). The mutual influence of both culture and leadership on one another exhibits a variety of advantages for the organisation, but interpretivism proposes the prioritisation of the culture first above leadership. As supported by Tsai (2011), organisational culture represents the overall values and beliefs of the organisation that even leaders are encouraged to adopt and implement. The close association between culture and leadership presents the leaders with the flexibility concerning changes in leadership styles as well as improvement in various aspects of culture. Thus, the extensive conceptual analysis of culture and leadership by Allaire and Firsirotu (1984) and Boromisza-Habashi (2012) presents a wider perspective of the relationship between the two aspects. In general, from the literature, the overall verdict on the association between culture and leadership depends on the position and standpoint of the researcher; however, both factors have a direct influence on one another.

\section{Research Methodology}

\subsection{Study Context}

This study was undertaken in Baidu Inc. Corporation, a multinational Internet services company headquartered in Beijing, China. Various factors facilitated the choice of Baidu as the case reference. The company's multinational nature means that its corporate culture is instrumental in the development of multiculturalism, and leadership is integral in the development of such factor. With the vastness of the organisation and various difficulties in the access of the information from the corporation, this study utilised a variety of research techniques to acquire enough data. The data presented the picture of Baidu's organisational culture and the influence on the type of leadership the company has opted for in their operations, both in China and abroad.

\subsection{Research Design}

This study employed a case study research design for the exploration of the question research question comprehensively. The appropriateness of the case studies as a methodological exploration strategy has been promoted by the flexibility of the research design and the ability to investigate and conceptualise various 
complex problems in real-world settings (Harrison et al., 2017). According to Zainal (2007), case studies have faced criticism for their lack of robustness; however, the writer acknowledges its ability to allow the researcher to explore complex issues. Given the nature of the study, the case study was likely to boost the qualitative approaches that prioritise the participation of the subjects in the study. It is an approach that emphasises on the essential nature of the individual's participation and character in both their cultural and social lives (Chowdhury, 2014). Hence, by using this research design, it significantly aided in the understanding of the social aspects of the study and the connection to the cultural environments.

\subsection{Mixed Research Methods}

A mixed research method is a process through which research adopts both the qualitative and quantitative study techniques within a single study to attain target results. This study utilised the mixed methods, combining both the qualitative and quantitative techniques in the data collection as well as the analysis process. In the analysis and compilation of the results, data triangulation enhances corroboration, convergence as well as correspondence of outcomes from different research methods. According to Schoonenboom and Johnson (2017), the primary objective of the researchers in using the mixed methods is to expand and strengthen the conclusions of the study, and also contribute to the published literature. Thus, for this study, both the qualitative and quantitative research methods were undertaken to enhance the extensiveness of the study process. Furthermore, the use of the mixed methods during this study ensured flexibility and effective process of data collection and analysis.

\subsubsection{The Use of Qualitative Methods}

The vastness of the Baidu as a corporate organisation meant that there was always going to be the availability of challenges in the effective examination of the people within their natural working settings. During the study, the qualitative method was used to gain knowledge into the values of the company, the cultural drives and the impacts on the leadership. According to Hammarberg et al. (2016), qualitative research is deemed appropriate when examining research questions concerning experience, meaning and perspective, mostly from the view and perception of the subject under study. Thus, in this study, interviews as qualitative data collection methods were administered to gain participant opinion concerning culture and leadership within Baidu Corporation.

\subsubsection{The Use of Quantitative Methods}

During the process of this study, the utilisation of the quantitative techniques was deemed appropriate for the collection of the significant quantitative data with a direct impact or significance to the outcomes of the research. As ascertained by Schoonenboom and Johnson (2017), the role of mixing the research methods is to enhance the depth of the research. In the same way, the quantitative methods for this study were utilised where there were limitations applying the qualitative techniques. For example, since getting direct interviews with every member of the Baidu corporate was practically difficult the study opted for the administration of the questionnaire to gather quantitative data with crucial impact on the outcomes of the results.

\subsection{Sources of Data}

The mixed-methods approach undertaken for this study necessitated a diverse choice of sources of the research data for this study. Thus, there was both the application of the primary data obtained from the study process, supplemented by secondary data to enhance the depth of the study process. Both the primary and the secondary sources of data provided an in-depth avenue for analysis in this study. The application of both the primary and the secondary data sources for this study process was encouraged by the increasing use of mixed methods to enhance expanded conclusions. While the primary data provided the first-hand information about the influence of organisational culture in Baidu, the secondary sources provided quality information about the industrial overview of the company's culture and leadership styles. Thus, both the primary data and the secondary data were instrumental in specific ways.

\subsubsection{Primary Data}

The first-hand data collected through the utilised data collection methods formed the primary data for the study. In this study, the sources of the primary data included telephone interviews scheduled and expected to get conducted among five heads of different sections, including the head of human resources in Baidu. Also, another source of the primary data included the administered online questionnaires, which provided a critical source of quantitative data that aided effective analysis and the compilation of the results.

\subsubsection{Secondary Data}

While the primary data formed the key foundation for the analysis, the availability of the relevant secondary data sources provided an extra option for the extensive analysis of the results. Most of the secondary sources suitable 
for this study process entailed the available industry information and data concerning the organisational practices obtained from the internet databases and the company's website. Another source of secondary data for this study was the relevant literature and statistics concerning the area of corporate culture and organisational leadership. The secondary information utilised was obtained from the databases with free use available for the public use within accepted practices. Therefore, with the existence of the vast sources of the secondary data, the primary data was extensively supported to enhance the depth of the study.

\subsection{Data Collection Methods}

Using the technique of the mixed method during the study process adds a new dimension in the collection of the data for the study. Nonetheless, the defining point emerges during the data collection process. Both the qualitative and quantitative data collection methods differ, and for this reason, the study opted to mix data collection methods with higher significance and relevance for the study. The primary goal was to obtain the most relevant data to address the research question and enhance validity and credibility. Therefore, this study used two major data collection methods, including the administering of the online questionnaire and telephone interviews.

\subsubsection{Questionnaires}

The administration of the questionnaire emerged as the best option to gain insights into the opinions and thoughts of several employees concerning the impact of their organisational culture on the leadership. The study administered email questionnaires to five different departments in Baidu. The feedback was expected after three weeks from the time of administration, and only granted one reminder of respondents to submit back the completed questionnaires on an optional basis. Thus, the study utilised mixed questionnaires, a type of questionnaire that combines both the open-ended and closed formatted questions and prevalent in the social sciences (Abawi, 2013). The need for a mixed questionnaire was to capture the extensive opinions of participants concerning their culture and leadership.

\subsubsection{Interviews}

With interviews being central in getting the key information concerning the opinions and perceptions of people within the organisation, the study emphasised the telephone interviews to gain feelings of the respondents. During the study, however, only one interview out of the scheduled five was completed, most significantly with the head of human resources in Baidu, who provided a clear picture on their cultural influence and leadership concerns within the corporation.

\subsection{Sample}

The study was carried out in Baidu Corporation, Beijing, targeting 100 participants. Among the key considerations in the sample characteristics were the number of male and female participants (gender), their age, and ethnicity. Given the anonymous nature of the study, the process relied mostly on the outcomes or the feedback of the study to establish the various traits in the number of respondents who were employees of Baidu. Ethnic origin, gender, and age as well the position held in the company were instrumental in obtaining key information for the qualitative analysis concerning the cultural influence of the company. Age, gender and ethnicity were rated the most significant attributes of the study population critical in supporting the actual image of Baidu corporate culture.

\subsection{Purposive Sampling}

The nature of the data obtained during the study prompted the need for the selection of an appropriate sampling technique during the study. Therefore, purposive sampling was preferred to retain critical aspects from the sample that would aid in the crafting valid conclusions. According to Tongco (2007), purposive sampling also referred to as judgment sampling, is the intentional selection of the data categories based on the qualities embedded in them that can advance the study needs. The researcher decides what to be known and seeks to utilise the values that can enhance the needs of the study. Therefore, the purposive sampling process in the course of this study was carried out along key attributes of the participants, as mentioned before. The sampling process was undertaken along with the age of participants, gender, and ethnicity. Purposive sampling is a technique that offers an easy process of analysis and it further helps in shaping a study's outcome in a direction deemed accurate.

\subsection{Ethical Considerations}

Ethical consideration is a significant aspect in the process of research since it positively impacts on the reliability and validity of research. The consideration of ethics in any research is fundamental, for it generates a clear guideline of researching. Moreover, it allows a researcher to avoid breaching personal boundaries and putting the 
subjects' at risk. Some of the ethical concerns that usually violate the ethical boundaries include the safety and privacy of the participants, religious beliefs, personal motives, and a sudden change in the course or objectives of a study. Researchers must uphold the highest ethical standards and guidelines, in particular, the ones that concern the participant's welfare, especially their anonymity and confidentiality.

The study involves human subject. The primary goal is to seek permission from the organisation and the Institution's Review Board (IRB) to allow the study process using human subjects. The subjects will be issued informed consent and inform them about the voluntary participation. This will be crucial since the two principles guarantee the involvement of subjects in their own free will and have been informed considering the research project's procedures and other potential risks. Some of the ethical considerations in the study include religious sensitivity, and personal beliefs wherein participants were excluded based on this criterion in case they felt it affected them.

\section{Results and Analysis}

\subsection{Response Rate}

This study was conducted with a target of one hundred respondents, of which 100 email questionnaires were administered. The response rate refers to the number of the people who answered the survey divided by the number of sample and usually expressed as a percentage (Fincham, 2008). Out of the one hundred questionnaires, 75 were successfully filled and submitted back via the email, while the remaining 25 were never received. Therefore, the response rate for this study can be determined as follows:

Number of responses $=75$

Number of the sample $=100$

Thus, $(75 \div 100) \times 100 \%$

$\therefore$ The response rate is $75 \%$

Table 1. The summary of response rate

\begin{tabular}{ll}
\hline Number of sample & 100 \\
\hline Completed responses & 75 \\
\hline Responses rate & $75 \%$ \\
\hline
\end{tabular}

In recent times, the expectations for the level of response rate have been raised. Hence, the researchers are expected to strive for the higher responses to avoid the deficit bias, and to make the study lose credibility. According to Fincham (2008)'s suggestions, a response rate with close to $60 \%$ and above is within the acceptable standards of the modern requirements of research responses. For this reason, this study's response rate of $75 \%$ falls within the acceptable rate for the evaluation of the subject under investigation.

\subsection{Participants Information}

\subsubsection{Participant Age Range}

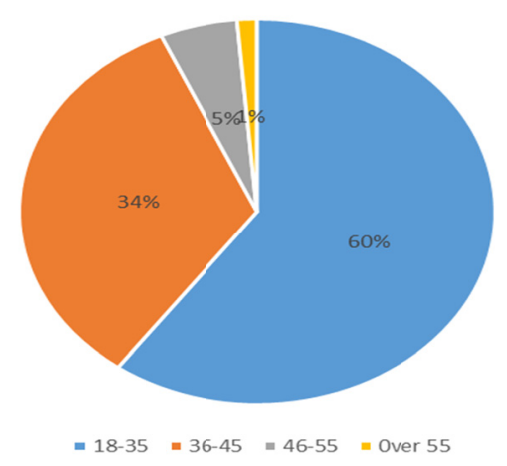

Figure 1. The age-range of the participants at Baidu 
From the feedback presented back, the majority of the workers who completed the survey questionnaire for the study consist of the majority of younger individuals. For example, $60 \%$ of the respondents are within the age range of between 18 and 35 years, while $34 \%$ of the total respondents fall within the age range of 36-45 years. From 46 to 55 and over 55 years, the overall percentage of each category is $5 \%$ and $1 \%$ respectively. The age outlines at Baidu reflect a vital aspect of the employment patterns of the firm. With Baidu being an internet service provider company, the number of younger professionals, who are tech-savvy and conversant with various technological needs, were expected to dominate the outcomes. Thus, the overall result of the majority of younger employees between the age of 18 and 35 correctly reflects the actual picture of the employment patterns in the technological world. Younger generations have a secure connection with technology, and Baidu's progress is based on the availability of the vibrant young workforce.

\subsubsection{Participant Gender Identity}

From the completed feedback, a total of $64 \%$ of the respondents indicated being male, while $29 \%$ highlighted that they were female. The remaining $7 \%$ of the respondents identified as "other' in the gender section. From the feedback, there is a notable gender gap when it comes to the workforce at Baidu. While the company seeks the best talent to enforce its goals, it is also apparent that there is a lack of gender balance. From the pie-chart represented below, the majority of the workers are male, followed by women and other gender categories. Thus, the reflection of gender balance within Baidu impacts directly on their corporate culture and leadership choices. In recent times, calls for the increased stability of gender at workplaces across the world have been intensified.

\section{Participant gender Identity}

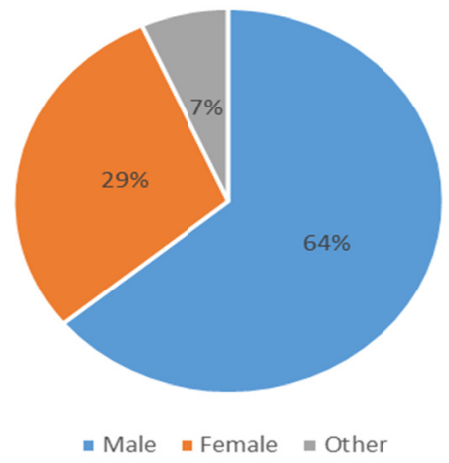

Figure 2. Gender identity of the participants

\subsubsection{Participant Ethnicity}

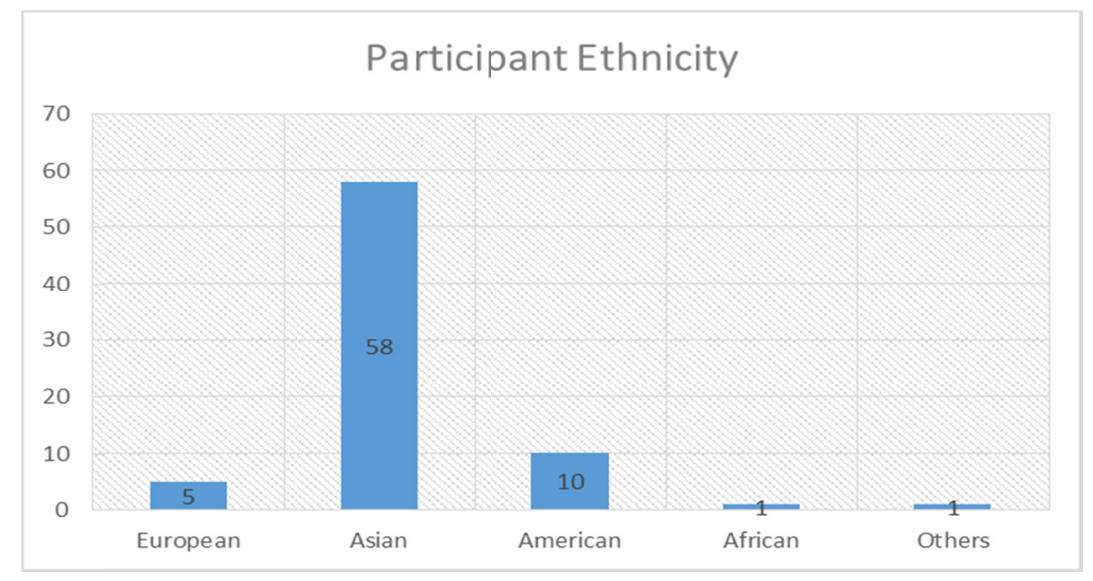

Figure 3. The ethnicity of the participants 
From the figure above, the majority of the workers at Baidu, Inc. China are of Asian origin. The gap in ethnic diversity at Baidu Corporation in china is large, such that other ethnicities like Africans and different categories are minimally represented. In this globalisation phase, the world is embracing multiculturalism and the need to have an ethnically diverse workforce. Since Baidu is a multinational corporation operating in most global regions, there is a chance that their employment criterion considers the business location. However, there are vital aspects that become associated with the scenario at the Baidu. In most instances, the cultural practices and leadership options at Baidu becomes affected by the available workers. The workers influence culture and formulation of the leadership styles, and the Chinese corporate culture has a unique way of addressing their leadership concerns as noted by Hawes and Chew (2011). Thus, Baidu's corporate culture and leadership options are most likely to get influenced by the Chinese values given the dominance of the workers from the Asian region. It is, therefore, imperative to underline that corporate culture is influenced by the available workers and the local values that drive the formulation of the leadership styles.

\subsubsection{Participant Position Distribution}

According to the feedback, Baidu's primary source of workforce recruitment is within the technology wing. From the participant response, Baidu's technological workforce comprises of $60 \%$ of the total workforce. Then other categories follow, with the administrative employees as well as the operations staff consisting of the $13 \%$ of the workforce each. The other categories, as well as the support staff, comprises of $7 \%$ each. With the majority of workers at Baidu being in the technology wing, it represents the actual picture of the company. Being primarily a technological company providing internet services across the world, it is right for the company to dwell on the work categories that affect their business. However, other work categories are essential for the successful running of corporate activities. For this reason, they play a central role in forming organisational culture, as well as determining suitable organisational leadership. The diversity in roles contributes massively to how the organisation culture shapes up, which eventually reflects in the management's choice of the leadership styles at Baidu Corporation.

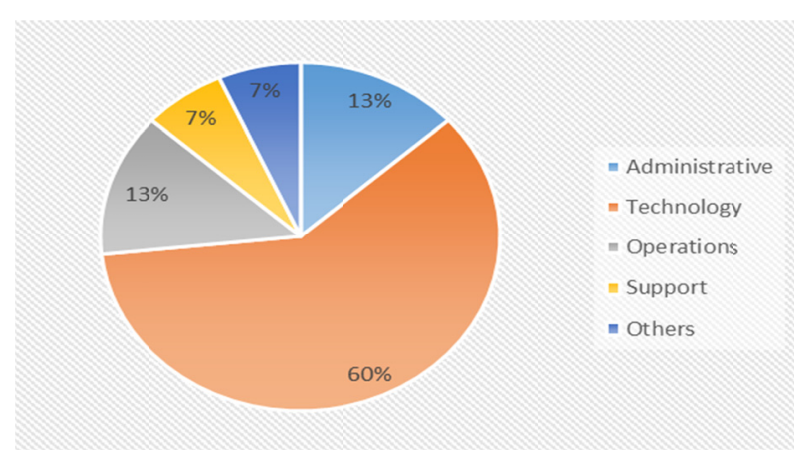

Figure 4. The participant position distribution at Baidu

\subsection{Baidu's Organisational Culture}

Central to Baidu's corporate activities is their culture defined by their working patterns, the number of employees, their characteristics and other aspects that influence their functionality. As supported by Aydin (2018), corporate culture is central to the formulation of secure practices and leadership patterns that propel the company towards higher performance. During the study, among the key objectives was to examine how the corporate culture affects the choice of leadership using the case scenario of Baidu. From the responses, there are numerous aspects of organisational culture that were evident.

\subsubsection{The State of Working Environment}

From the answers, $73 \%$ of the participants believed that their working environment was friendly, highlighting an overall positive perception of Baidu's corporate culture. However, a considerable number at $21 \%$ opted to note that the working environment at Baidu was strict, while only $6 \%$ believed that the working environment was hostile. From the respondents' results, there is a clear indication of a favourable working environment at Baidu. 


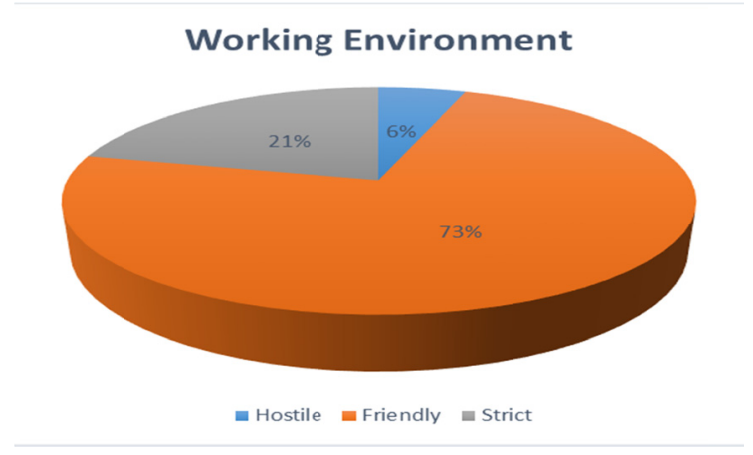

Figure 5. Participant's feeling on the working environment

\subsubsection{Organisational Teamwork}

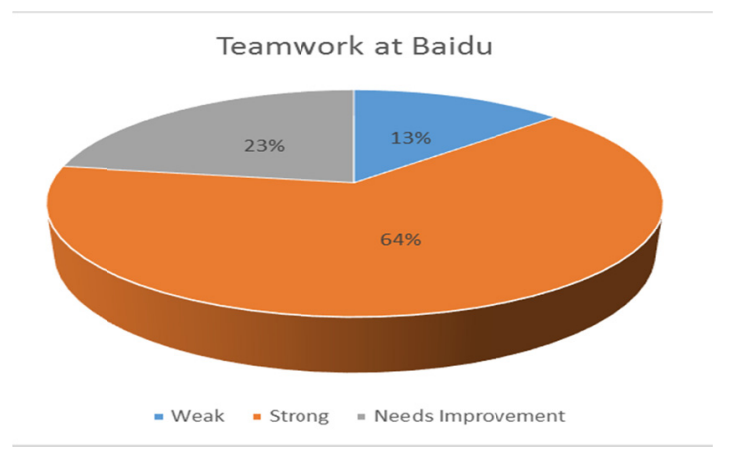

Figure 6. Participant opinion on teamwork at Baidu

When asked about the state of cooperation within Baidu, the majority of the respondents at $64 \%$ asserted that the company has an influential teamwork culture, while $32 \%$ still believed that there a need for improvements. $13 \%$ of the participants are of the view that Baidu's teamwork culture is weak. There is a considerable mixture of expressions. The total combination of the workers who believe that the company has a weak culture or needs improvement stands at a combined percentage of $36 \%$, which is massive. However, a majority of them were still satisfied with the teamwork culture. These are aspects that directly impact on organisational culture and leadership.

\subsubsection{Work-life Balance at Baidu}

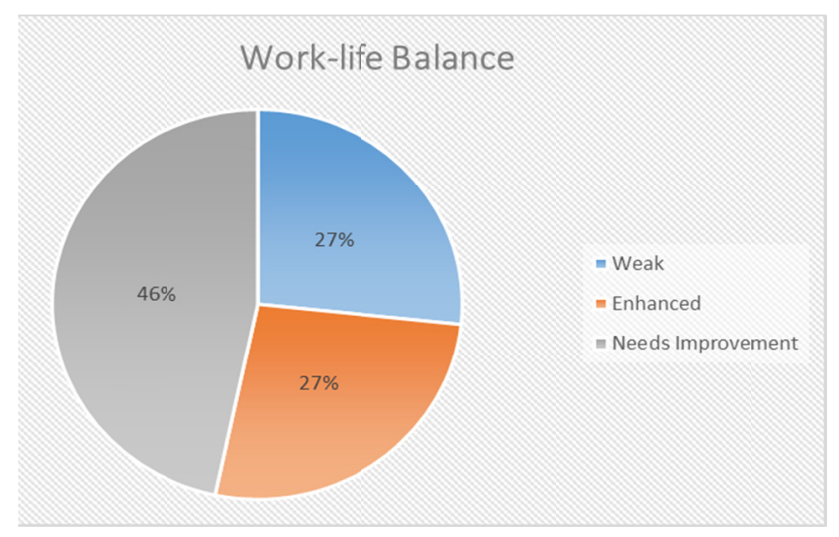

Figure 7. Participant's opinion on work-life balance at Baidu 
Interesting patterns emerged when the workers were asked to opine on their work-life balance at Baidu. The majority of them were clear on the matter, with $46 \%$ of the respondents stating that the work-life balance at Baidu needs improvement. On the other hand, the results also revealed an equal percentage of the workers at $27 \%$ who felt that work-life balance was weak, and those who thought it was enhanced. Work-life balance is an integral aspect of the life of the worker in the modern corporate world. It is a working culture that most organisations have come to take seriously to enhance the happiness of their workers. Most workers at Baidu do not believe that their work-life balance is enhanced, and it is a pattern that gauges the company's leadership in the treatment of employees.

\subsubsection{Workplace Schedule}

Table 2. Opinion on work schedule in Baidu

\begin{tabular}{ll}
\hline State of work schedule & The percentage of respondents \\
\hline Tight & $25 \%$ \\
\hline Balanced & $45 \%$ \\
\hline Needs Improvements & $30 \%$ \\
\hline
\end{tabular}

Working schedules instrumental in the daily working processes of the employees as it enables them to plan for their working activities. From the research conducted during this study, only $45 \%$ of the workers at Baidu felt that their work schedules were balanced. $25 \%$ of the respondents highlighted the strict nature of the working process at Baidu, and further $30 \%$ felt that the working schedule needs improvements at the company. The working schedules within larger corporations such as Baidu are a greater part of the organisational culture advanced by the leadership techniques enhanced in the company. Leadership within an organisation determines the work processes, and most instance, the pressure the employees would feel during working hours depends on the intense programs set by the management. In most cases, a corporate culture that employs transformational leadership is most likely to satisfy the needs of its workforce through participatory working procedures. On the other hand, the transactional leadership model places massive power on the leaders, while workers perform their duties in obedience while expecting returns (Simpson, 2012). In numerous corporate entities, transactional models are utilised to enhance the profit-making goals of the firms, but this sometimes comes at the expense of the workers' social welfare.

\subsubsection{Worker-Leader Relationship}

Table 3. Worker-leader relationship at Baidu

\begin{tabular}{ll}
\hline State of the Worker-leader Relationship & Responses from the workers \\
\hline Interactive & $35 \%$ \\
\hline Hierarchical & $60 \%$ \\
\hline Needs improvements & $5 \%$ \\
\hline
\end{tabular}

Another critical aspect in the corporate culture is the relationship between the workers and the corporate leaders who are also the supervisors. During the study, a large percentage $(60 \%)$ of the respondents believe that Baidu's work-leader relationship is highly hierarchical. $35 \%$ of the participants noted that the relationship is interactive, while only $5 \%$ felt that the association needs improvements. The feeling in the company among the workers is that the relationship between the workforce and the company leadership is based on the bureaucratic system. In most instances, a hierarchical culture often limits the power of the average employee, and the possible association is centred on orders and obedience. Corporate culture and the leadership styles adopted determine the kind of relationship the employees have with their bosses. In this case, the majority of the employees at Baidu have a strong belief that they are led hierarchically. The motivation behind these kinds of systems depends on the goals and objectives of the organisation, but Kouzes and Posner (2015) noted that leadership should be inspirational and enable the followers to act. 


\subsubsection{Worker Opinion on Culture and Leadership}

Employees are the direct subjects affected by the organisational culture as well as the leadership styles adopted to advance the operations and the objectives of the business. The opinions of the workers at Baidu concerning the ways of improving their working environment and their overall culture reveals key patterns in the relationship between the organisational culture and leadership styles. From the investigated aspects, it is imperative to underline that organisational culture is integral in determining various work environment aspects. From the relationship between the workers and their supervisors to the cooperation among the workforce; a proper culture creates a roadmap for a leader in adapting and enhancing the right practices for enhanced performance. While some leaders dwell on getting the best out of the employees, others expect the employees to perform relentlessly (Simpson, 2012). The common opinion from most workers at Baidu indicates a more traditional corporate culture that prioritises bureaucratic tendencies and hierarchical order, with relatively tight work schedules, and a less enhanced work-life balance. Most employees cite a balance in the working schedules, and the balance between work and social life as imperative in the company's culture to enhance vibrancy in the workforce.

\subsection{Organisational Leadership}

Being at the centre of cultural influence, organisational leadership became an important aspect of investigation during this study. From the responses, various facts emerged that reflects on the influence of the corporate culture on leadership styles. This study sought to establish key leadership patterns according to the opinions of the workers in Baidu. From the results, key aspects emerged that reflect how corporate culture and a set of practices impact on the type of leadership an organisation adopts. The study intended to highlight the leadership patterns and their connection with the set corporate culture at Baidu within China. Among the key considerations involved matters concerning the relationship between the seniors and juniors at work in the leadership and follower roles, the workers' preferred leadership styles, and how the existing system affects their performance, perception as well as the interactions. It is vital to remember that all these unfold within a set corporate culture (Nikcevic, 2016). From the study, the key findings obtained from the workers concerning the aspects such as the set of work practices and activities, as well as the control over them by their seniors, was instrumental. It established the influence of corporate culture on leadership.

\subsubsection{The Leadership Style Adopted at Baidu}

During the study, among the fundamental objectives were to examine what kind of leadership Baidu employee believed their organisation adopted. The corporate culture must have leadership styles that employees understand or can quickly identify with. From the analysis of the Baidu's corporate culture based on the respondents' feedback, it became possible to draw the link to their leadership style adopted in the control of the activities and workers. The examination of the leadership styles within the company was based on three main techniques that are commonly applied in the corporate scenario: bureaucratic, transformational and transactional. When asked to highlight the leadership style they believed existed in their organisation, the respondents responded as illustrated in the figure below.

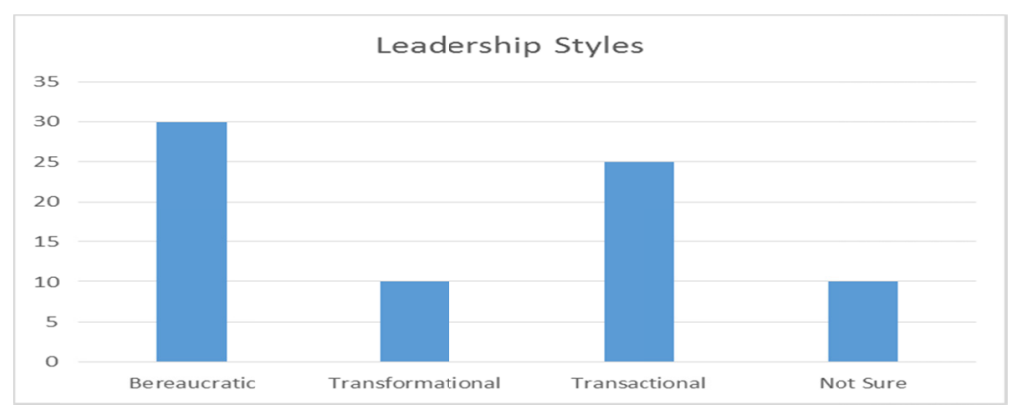

Figure 8 . The types of leadership styles the employees believed existed in Baidu

According to the respondents, 30 of them thought that Bureaucratic leadership style was the dominant control system in Baidu. Similarly, 25 participants believed that Baidu's leadership style is Transactional. Only 10 respondents underlined that Transformational leadership style guided them, while a further 10 noted that they 
were not sure. In some cases, there can be a close association between transactional and bureaucratic styles of leadership. Both involve orders from the seniors and the obedience from the juniors. However, Simpson (2012) differentiated the two methods, whereby in the bureaucratic system, the leader acts an enforcer of the commands and duties, while in the transactional style, obedience in the performance based on the rewards is the order of the association. Baidu's corporate culture is built on the hierarchy, and these systems are often associated with the bureaucratic and transactional leadership styles. As confirmed by many respondents, there is a low likelihood of transformational leadership in such a culture.

\subsubsection{Confidence in Leadership Style Adopted}

The study sought to examine the extent to which respondents had confidence in the type of leadership styles they believed their organisation adopted. 53\% declined that they did not have faith, while $40 \%$ confirmed that they had confidence in the leadership of the company. $7 \%$ of the participants were not sure, and the figure below summarises the outcomes of the responses.

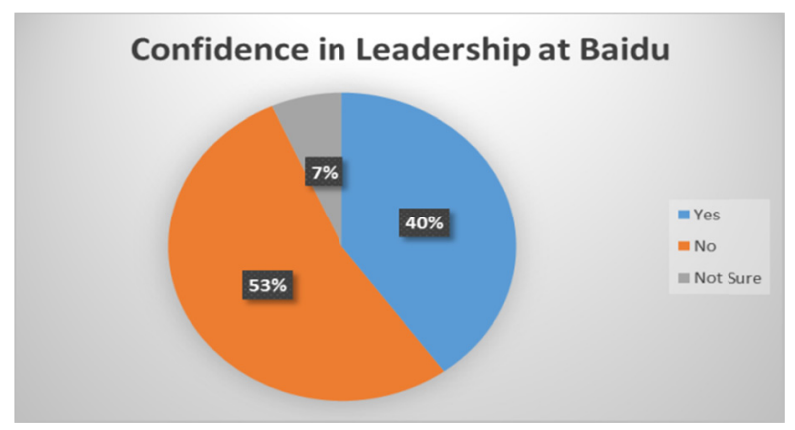

Figure 9. The workers' confidence in the leadership of Baidu

The type of corporate culture adopted and the leadership style for the control of the organisation determines whether the employees would trust their leaders or not. In most cases, leadership styles such as transformational tend to develop a strong bond between the leader and the follower. On the other hand, while bureaucratic leaders may only be enforcers, a bad individual enforcer could lead to negative perceptions from the employees. On the other hand, transactional leadership is based on expectations from both the leader and the follower. From the responses outlined, the confidence of the people in the leadership depends on the personal experiences they had at various levels with individual leaders at multiple levels. A thriving corporate culture houses effective leadership styles that earn the confidence of the employees in all ways.

\subsubsection{Preferred Leadership Styles Among Workers}

When asked about their preferred leadership style that they thought would suit them at their organisation, the majority of the respondents (55\%) favoured the transformational leadership style as the best choice to guide them forward and enhance their performance. On the other side, a considerable percentage of the participants (25\%) still believed that the bureaucratic system could get the best out of them while another $15 \%$ still liked the transactional style of leadership. Only $5 \%$ of them preferred other styles.

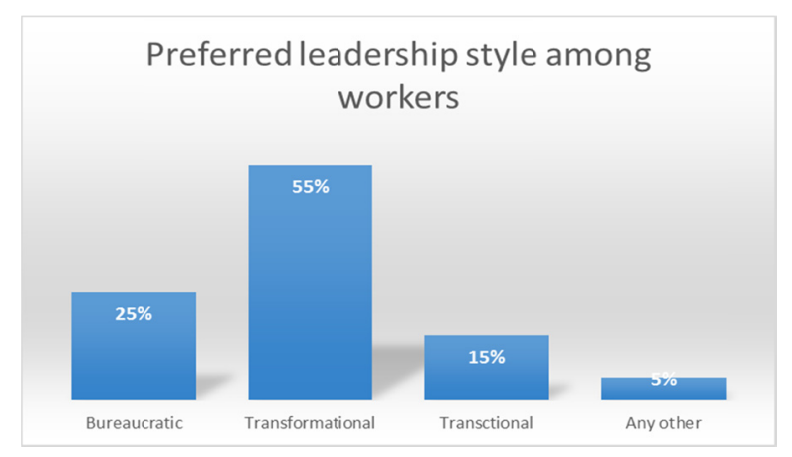

Figure 10. The preferred leadership styles among the workers 
From the responses, the majority of the workers at Baidu still think that transformational leadership is the best style of leadership within a corporate culture within their work environment. From Simpson (2012)'s analysis, transformational leadership provides the perfect conditions for the workers. The critical aspects associated with this kind of leadership involve inspirational motivation, individualised consideration, idealised influence and intellectual stimulation. Transformational leadership is the ultimate style that considers the social and intellectual well-being of the worker. However, in a corporate context, the desire and drive for financial performance, and generation of profit sometimes leads to the development of the organisational cultures with strict practices, all aimed at a higher performance. In this case, bureaucratic leadership has often dominated the corporate world and the transactional leadership in profit-oriented firms.

\subsubsection{Leadership and Reflection of Culture}

During the study, the respondents were asked to highlight whether the leadership style adopted reflected the culture at their organisation. $76 \%$ of them acknowledged that the leadership style they believed taken in Baidu reflected the corporate cultural values of the company. $20 \%$ declined that the leadership style adopted at Baidu did not reflect the cultural values of the company, while $4 \%$ were not sure. From the responses, the majority of the workers have a strong belief that the leadership style used to guide them is a product of cultural outline of the firm. Regardless of the leadership style that individual workers preferred or believed existed in the organisation, there was an active link between culture and the leadership style used.

\section{Leadership and the Reflection of Culture}

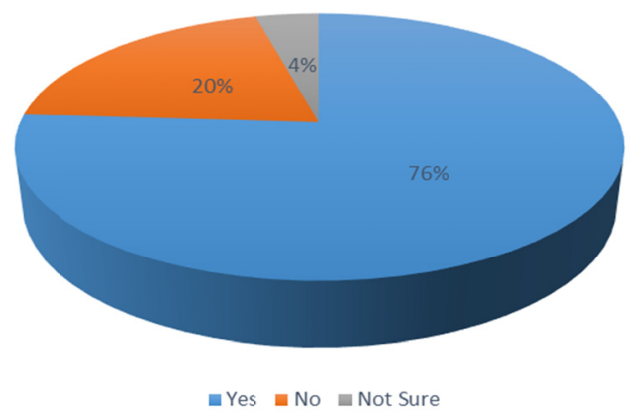

Figure 11. Workers' perceptions of leadership and reflection on culture

\subsubsection{Worker Opinion on Organisational Leadership}

Baidu's corporate culture forms a strong basis for the leadership style implemented in the company within China. There is varied opinion concerning the culture and leadership fundamentals of the organisations. However, it is imperative also to underline that these views are based on personal experiences and judgement of the working situation and that is why there is a significant difference. Most of the respondents aired their opinions based on what they believed they should get from the organisation. From the responses, there were mixed feelings on whether the current leadership at Baidu can get the best out of the team. For this reason, some of the employees felt that they could change some corporate culture and leadership factors to enhance a better working environment.

Table 4. The worker opinion on leadership aspects

\begin{tabular}{lll}
\hline State of leadership & Employee opinion (Yes) & Employee opinion (No) \\
\hline $\begin{array}{l}\text { The existing administration gets the best out } \\
\text { of the worker }\end{array}$ & $56 \%$ & $44 \%$ \\
\hline $\begin{array}{l}\text { Organisational leadership needs change or } \\
\text { remain the same }\end{array}$ & Needs change-57\% & Should remain the same-43\% \\
\hline
\end{tabular}

The overall view of the workers is that they could have an active role to play in the transformation of the 
corporate culture at Baidu, which directly affects the outcomes of leadership at the company on various levels. From the analysis of the opinion concerning the corporate culture of Baidu, the influence of organisational culture becomes apparent.

\subsection{Role of Corporate Culture}

From the results and the analysis section, corporate culture plays an integral role in shaping organisational leadership. It has a direct influence on what transpires within the ranks of authority in the firm. However, there are other numerous factors to consider as well, given the formation of the culture is something influenced by the values of the people behind the creation of the business. According to Sukkar (2017), culture influences organisational leadership. However, the formation of the culture differs from one place to another. The cultural perception of an organisation the European countries broadly differ from that in the Asian nations. Hawes and Chew (2011) highlighted the bureaucratic nature of most Chinese companies. In this case, top executives remain the primary enforcers of the significant commands and orders. Organisational culture is highly influenced by the local values, but most significantly, by the role of a multicultural and diverse workforce. There is an apparent lack of diversity in many of the top Chinese companies, and this also impacts the styles of leadership adopted. For instance, Sukkar (2017) highlighted that cultural influence affects people from different regions, not only on individual levels but also during the interactions with other people. The social norms and values differ from one region to another, and the corporate culture of Baidu in China is most likely to follow the patterns of the Chinese organisational outline.

\subsection{The Link Between Culture and Leadership}

The connection between culture and leadership within an organisation is mutual, and as the culture develops over-time, it becomes a building block of leadership in an organisation. Nonetheless, culture has always been a non-constant issue. As supported by the views and the opinion of the respondents, there was a significant feeling that some aspects of the organisations could be changed. In the same way, cultures can change (Aydin, 2018), but in this process, they are also at risk of being manipulated to suit individual goals of a leader. For the corporate entity like Baidu operating in several regions, dealing with multiculturalism is critical. For example, According to Forbes (2013), Baidu is more like a product of Silicon Valley, with its founder Robin Li, having been a former employee at the Silicon Valley. The common belief is that Baidu is built on the values similar to those of American tech society. However, it is also possible that the company's various businesses in many locations promote disparity in its social values. In China, Baidu has to adapt to the expected level of corporate culture and leadership expectations to compete. In the same way, the company would adopt a relevant organisational structure in the US, Brazil and any other country it operates.

\subsection{The Influence of Culture on Leadership}

Consequently, as the corporate culture shapes, the leadership styles follows, and at some point in the company's life-cycle, changes in the leadership can contribute to the resultant evolution of culture. Baidu's corporate culture is the basis of their leadership style in China, and this directly impacts on the working environment. The recipient of the leadership techniques in any organisation are the employees, and for this reason, culture is a significant aspect of their existence in the corporate world. Employees prefer leadership styles that enable them to get involved in important matters and decision-making directly, but this is not the case in many firms with bureaucratic cultures. Kouzes and Posner (2015) noted that leaders have a responsibility of building a culture to enable others act and develop. In this case, leaders become the creators of culture so that it can influence their actions and leadership traits. While they can influence the outcomes of culture, including manipulating it, it is still within the same culture that leaders would execute their leadership plans. Thus, no organisation can exist without a culture, and the results from Baidu indicate a strong influence of the local corporate culture on their activities. From the analysis, it is also apparent that the people within a culture may be open to changes, especially when they deem it as a necessary factor.

\section{Conclusion}

Leadership and culture are critical factors in the shaping of the organisations and the creation of the operational paths. From the case study of Baidu, numerous conclusions can be drawn similar to other corporate scenarios across the world. There are valid reasons why managers should pay attention to culture as a component of the organisation. First of all, culture is integral in shaping organisational performance and practice, as well as the establishment of corporate identity (O'Donnell \& Boyle, 2008). Culture creates values, rituals and beliefs from the past that new employees would learn as legends as they comprehend dos and don'ts in their new working environment. The evolvement of organisations sees massive changes, sometimes in their cultural practices. As culture shapes leadership, over time, the process of organisational change and transformation affects various 
components of culture. What is evident in Baidu is that workers feel there are some aspects they think could be changed to enhance efficiency. Also, Aydin (2018) underlined that cultures could be prone to manipulation or change by the leaders. The process of initiating change by the leader can be crucial only if it is done for the best of the firm. Martin (2013) warns culture can be a very critical aspect during the organisational change process, which could lead to either success or failure. It is both a blessing and a curse. Thus, when leaders aim to change various practices of the culture, they should also be careful that their actions do not impact negatively on the company's progress.

Conversely, as earlier found and highlighted throughout this study, the key to thriving organisational culture is leadership. The success or failure of the organisation is based on the leadership modes that the organisation adopts. For a more extended period, the bureaucratic system of governance has proved to be a practical aspect of leadership commonly used in many organisations. However, Simpson (2012) reckons that it is a system that only grants the seniors the power to enforce and the juniors to carry out implementation. In recent times, the calls for the organisational leadership transformation have seen calls for the adoption of styles such as transformational leadership, which creates a fair environment for the employees to get involved. Culture strongly influences the leadership a company adopts or decides to change to enhance competitiveness. Cultural elements such as the shared values, the organisational rituals, practices and patterns can be either instrumental or detrimental. The most significant function of culture is that it enables the leaders to gauge and determine the best for the company. Thus, the ability of culture to be changed through leadership presents an excellent opportunity for the enhancement of positive changes. Times are rapidly changing, and the increased competition means that companies need to adapt to the latest changes to stay relevant (Rijal, 2016). In the technological field, organisations such as Baidu face stiff competition from others such as Yandex and Google. Thus, to stay as a stronger competitor, Baidu needs to utilise leadership to enhance positive cultural changes centred on innovation and creativity.

Consequently, leadership is key to the progress of all the organisational goals. As found before in this study, employees within a corporate, who are a critical part of the culture, have their perceptions of perfect leadership. As discovered, the majority of the workers prefer a transformational form of leadership. Nevertheless, it is also significant to underline that these leadership styles depend on the ability of the leader in executing his or her plans. Regardless of the leadership style stipulated within an organisation, an incapable leader will always find himself or herself on the wrong end with less inspiration for his/her followers. Adopting transformational leadership also requires a leader with the ability and characteristics to inspire, and should also be charismatic. Also, he or she should promote intellectual stimulation among his/her team and also recognising that every employee has specific concerns, needs and desires. Commonly, most of the leaders in the corporate environment flourish under the bureaucratic systems, with their primary functions being only to enforce rather than to inspire.

Thus, a productive culture sets the tone for the implementation of the leadership styles that suit the needs of the company. Culture and leadership are closely related and complement each other, but an organisation must first exist with a set of cultural patterns before the implementation of leadership forms. The leaders' role is to uphold the fundamentals of culture by adapting to its demands or changing the culture in response to the possible internal and external calls for change. When culture grows old or outdated within a corporate scenario, it calls for a change, and for a successful transformation, only effective leadership is required. Leadership should suit the demands of corporate cultures for enhanced sustainability but a leader must adhere to the useful cultural outlines that control and guide the organisational activities.

\section{References}

Abawi, K. (2013). Data Collection Instruments: Questionnaire \& Interview. Reteived from https://www.gfmer.ch/SRH-Course-2012/Geneva-Workshop/pdf/Data-collection-instruments-Abawi-2013. pdf

Akhavan, P., Zahedi, M., Dastyari, A., \& Abasaltian, A. (2014). The effect of organizational culture and leadership style on knowledge management in selected research organizations. International Journal of Scientific Management and Development, 2(9), 432-440.

Allaire, Y., \& Firsirotu, M. (1984). Theories of Organisational Culture. Organisation Studies, 5(3), 193-226.

Alnasseri, N., Osborne, A., \& Steel, G. (2013). Organizational culture, leadership style and effectiveness: a case study of Middle Eastern construction clients. In Procs 29th Annual ARCOM Conference (pp. 393-403). Reading, UK: Association of Researchers in Construction Management.

Al-Tameemi, K., \& Alshawi, M. (2014). The impact of organisational culture and leadership on performance improvement in Iraq. The Built \& Human Environment Review, 7, 1-15. 
Aripin, Salim, U., Setiawan, M., \& Djumahir. (2013). Implications of Organizational Culture and Leadership Styles the Effects on Job Satisfaction and Organizational Performance of Police Sector in Bandung, Cimahi, Garut- West Java. IOSR Journal of Business and Management (IOSR-JBM), 7(5), 44-49.

Aydin, B. (2018). The Role of Organizational Culture on Leadership Styles. Manas Journal of Social Studies, $7(1), 267-280$.

Boromisza-Habashi, D. (2012). Interpretivist approach to culture. In A. Kurylo, (Ed.), Inter-Cultural Communication: Representation and Construction of Culture (pp. 305-328). Thousand Oaks, CA: Sage.

Chowdhury, M. (2014). Interpretivism in Aiding Our Understanding of the Contemporary Social World. Open Journal of Philosophy, 4, 432-438.

Dauber, D., Fink, G., \& Yolles, M. (2010). A Generic Theory of Organizational Culture. SMA 2010 Proceedings (pp. 28-33).

Fincham, J. (2008). Response Rates and Responsiveness for Surveys, Standards, and the Journal. American Journal of Pharmaceutical Education, 72(2), 1-3.

Forbes. (2013). What Is The Internal Culture Like At Baidu? Retrieved from https://www.forbes.com/sites/quora/2013/03/29/what-is-the-internal-culture-like-at-baidu/\#4b0e0ea5c620

Hammarberg, K., Kirkman, M., \& de Lacey, S. (2016). Qualitative research methods: when to use them and how to judge them. Human Reproduction, 31(3), 498-501.

Harrison, H., Birks, M., Franklin, R., \& Mills, J. (2017). Case Study Research: Foundations and Methodological Orientations. FQS, 18(1), 1-17.

Hawes, C., \& Chew, E. (2011). The Cultural Transformation of Large Chinese Enterprises into Internationally Competitive Corporations: Case Studies of Haier and Huawei. Journal of Chinese Economic and Business Studies, 9(1), 67-83.

Hersey, P., \& Blanchard, K. (2014). The management of organizational behavior (4th ed.). Englewood Cliffs, NJ: Prentice-Hall.

Jalal, A. (2017). Impacts of Organizational Culture on Leadership's Decision-Making. Journal of Advances in Management Sciences \& Information Systems, 3, 1-8.

Klein, A., Wallis, J., \& Cooke, R. (2013). The impact of leadership styles on organizational culture and rm effectiveness: An empirical study. Journal of Management \& Organization, 19(3), 241-254.

Kouzes, J., \& Posner, B. (2015). The Leadership Challenge: How to Make Extraordinary Things Happen in Organizations (5th ed.). San Francisco, CA: Jossey-Bass.

Lousa, E., \& Monico, L. (2018). How can leadership and organizational culture predict innovation in small, medium and large enterprises?. The Journal of Organizational Management Studies, 1-115.

Martin, J. (2013). Organizational Culture and Organizational Change: How Shared Values, Rituals, and Sagas can Facilitate Change in an Academic Library. Retrieved from http://www.ala.org/acrl/sites/ala.org.acrl/files/content/conferences/confsandpreconfs/2013/papers/Martin_O rg\%20Culture.pdf

Nikcevic, G. (2016). The influence of organizational culture on leadership - case study Montenegro. Tehnički Vjesnik, 23(1), 191-197.

O’Donnell, O., \& Boyle, R. (2008). Understanding and Managing Organisational Culture. Retrieved from https://www.ipa.ie/_fileUpload/Documents/CPMR_DP_40_Understanding_Managing_Org_Culture.pdf

Pennington, P., Townsend, C., \& Cummins, R. (2003). The Relationship of Leadership Practices to Culture. Journal of Leadership Education, 2(1), 27-44.

Rahmisyari. (2015). Effect of Leadership Styles, Organizational Culture, and Employees Development on Performance (Studies in PT. PG. Gorontalo of Tolangohula Unit). International Journal of Business and Management Invention, 4(1), 85-91.

Rijal, S. (2016). Leadership Style And Organizational Culture In Learning Organization: A Comparative Study. International Journal of Management \& Information Systems - Second Quarter, 20(2), 17-26.

Schoonenboom, J., \& Johnson, R. (2017). How to Construct a Mixed Methods Research Design. Kolner Z Soz Sozpsychol, 69(2), 107-131.

Simpson, S. (2012). The Styles, Models \& Philosophy of Leadership. Retrieved from 
http://www.sustainicum.at/files/projects/268/en/handouts/the-styles-models-philosophy-of-leadership.pdf

Sukkar, A. (2017). Culture Influences and Leadership Theories, a Case Study: Egyptian Culture. Journal of Basic and Applied Research, 3(4), 133-135.

Szczepańska-Woszczyna, K. (2015). Leadership and Organizational Culture as the Normative Influence of Top Management on Employee's Behaviour in the Innovation Process. Procedia Economics and Finance, 34, 396-402.

Tongco, D. (2007). Purposive Sampling as a Tool for Informant Selection. Ethnobotany Research \& Applications, 5, 47-158.

Tsai, Y. (2011). Relationship between Organizational Culture, Leadership Behavior and Job Satisfaction. BMC Health Services Research, 11(98), 1-9.

Zainal, Z. (2007). Case study as a research method. Jurnal Kemanusiaan Bil, 9, 1-6.

Zhang, S., \& Liu, A. (2006). Organisational culture profiles of constructionenterprises in China. Construction Management and Economics, 24, 817-824.

\section{Appendix}

A Questionnaire Survey Sheet for Baidu, Inc. China

Conducted by [Yinfei Xue]

Participant information sheet

Dear [insert name of participant]

You are invited to take part in a study that is being conducted for a research project as part of the Master's degree in FT Management at Queen Mary University of London.

This is a research questionnaire seeking your views concerning the organisational culture and its effects on leadership of the firm. It is important to note that your participation is voluntary, and your genuine feedback is highly appreciated. The study intends to treat the feedback seriously, and strictly confirm that it is intended only for academic purposes.

The interview will take roughly 5 minutes and can be held at a time and place that is convenient for you.

If you decide to take part in the study, you will be asked a series of questions, however, you do not have to answer any question if you do not wish to and you are able to withdraw from the study at any time. Prior to the interview you will be asked to sign a consent form that outlines more about your rights during the project and guarantees confidentiality of your information. The interview will be recorded and will later be transcribed. This will enable me to capture what is said in the interview without being distracted by the need to take notes. However, you can ask not to have your interview recorded or ask to have the recording device stopped at any time during the interview. Your transcribed interview will be kept for 12 months in a secure place and then destroyed.

Once all interviews have been conducted, a transcription / detailed notes will be analysed and examined in an anonymised form, and compared with information from other interviewees. No information that could identify you as an individual will be used in writing up the research.

The research will be written up in the form of a dissertation to be submitted as a requirement for my MSc degree. Although the dissertation itself is not published, academic publications based on this work may also be developed. These too will be anonymised, both with respect to individual interviewees and their organisations.

A copy of the transcribed interviews and the final dissertation can be made available to you on request.

Kind regards,

Yinfei Xue 


\section{Part One: Participant Information}

Tick appropriately in the box $[\sqrt{ }]$
1. Age range: $18-35$ [ ]
$36-45[$ [ ]
$45-55[]$
Over 55 [ ]

2. Gender: Male [ ] Female [ ] Other [ ]

3. Ethnicity: European [ ] African [ ] American [ ] Asian [ ] Other [ ]

4. Position held: Administrative [ ] Technology [ ] Operations [ ] Support [ ] Other [ ]

\section{Part Two: Organisational Culture}

Choose one item e.g. A

5. How can you term your working environment?

A. Friendly B. Hostile C. Strict

6. How can you term teamwork in your organisation?
A. Strong
B. Weak
C. Needs improvement

7. How is work-life balance in your organisation?

A. Enhanced B. Weak C. Needs improvement

8. How can you term your work schedule?

A. Tight B. Balanced C. Needs improvement

9. How can you term your relationship with your supervisors

A. Interactive B. Hierarchical C. Needs improvement

10. In your own words, describe your working experience at Baidu

11. State briefly how you feel your working culture could be improved.

\section{Part Three: Organisational Leadership}

Tick appropriately in the box $[\downarrow]$

12. What is the form leadership style does your organisation employ?

[ ] Bureaucratic [ ] Transformational [ ] Transactional [ ] Not sure

13. Do you have confidence in the leadership style adopted in your workplace?

[ ] Yes [ ] No

14. What would be your preferred leadership style for your working organisation?

[ ] Bureaucratic [ ] Transformational [ ] Transactional [ ] Not aware

15. Do you believe that the leadership adopted reflects the cultural beliefs of your organisation?

[ ] Yes [ ] No [ ] Not Sure

16. Describe your relationship with your supervisors using e.g. formal, strict, friendly, rigid or flexible

17. In your own opinion, do you believe that the existing leadership gets the best out of you?

18. Give reasons why your organisational leadership needs to change or needs to remain the same

19. In your opinion, mention ways in which your organisation can enhance effective leadership if you feel it does not suit you.

20. In your opinion, highlight how you would maintain your organisation's leadership if you feel it is up to the standards. 


\section{Participant Consent Form}

I have read the Information Sheet and have had the details of the study explained to me. My questions have been answered to my satisfaction, and I understand that I may ask further questions at any time.

I understand I have the right to withdraw from the study at any time and to decline to answer any particular questions.

I agree to provide information to the researcher(s) on the understanding that my name will not be used without my permission (The information will be used only for this research and publications arising from this research project.)

I understand that I have the right to ask for the recording device to be turned off at any time during the interview.

Please tick:

I agree to the interview being recorded.

I do not agree to the interview being recorded.

I agree to participate in this study under the conditions set out in the Information Sheet.

\begin{tabular}{ll}
\hline Name of Participant $\quad$ Date \\
\hline
\end{tabular}

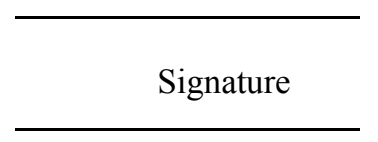

End.

\section{Copyrights}

Copyright for this article is retained by the author(s), with first publication rights granted to the journal.

This is an open-access article distributed under the terms and conditions of the Creative Commons Attribution license (http://creativecommons.org/licenses/by/4.0/). 